\author{
Agentes Vesicantes \\ Colasso, C. G.;* França, T. C. C. \\ Rev. Virtual Quim., 2014, 6 (3), 724-743. Data de publicação na Web: 15 de abril de 2014 \\ http://www.uff.br/rvq
}

\title{
Vesicant Agents
}

Abstract: Despite less toxic than the neurotoxics, the vesicant agents show the same lethality. The sulfur mustard, the main vesicant, was largely used during World War I, and among the warfare agents, was responsible for the largest number of casualties in history. This fact has yielded to this vesicant the nickname of King of the warfare gases. Other feature of the vesicants is their capacity to leave profound sequelae in its victims as a result of the feared "chemical burns". In this work we present a small revision of on the historical aspects, the physical chemical properties, the toxicology and the available treatment against vesicants.

Keywords: Vesicant agents, mostards, chemical warfare.

\section{Resumo}

Os agentes vesicantes, embora menos tóxicos que os neurotóxicos, são igualmente letais. A mostarda de enxofre, o principal agente vesicante, foi largamente empregada durante a I Guerra Mundial, sendo responsável pelo maior número de baixas relacionadas a agentes químicos durante a guerra. Fato que rendeu a esse vesicante a alcunha de rei dos gases de guerra. Outra peculiaridade dos vesicantes, que os distingue dos demais agentes, é sua capacidade de deixar sequelas profundas em suas vítimas resultantes das temidas "queimaduras químicas". Esse trabalho apresenta uma mini revisão dos aspectos históricos, das características físico-químicas, da toxicologia e dos tratamentos disponíveis atualmente contra os vesicantes.

Palavras-chave: Agentes vesicantes, mostardas, guerra química.

\footnotetext{
* Instituto Militar de Engenharia, Laboratório de Modelagem Aplicada à Defesa Química e Biológica (LMDQB), Praça General Tibúrcio 80, CEP 22290-270, Rio de Janeiro (RJ), Brasil.

M camillacolasso@gmail.com

DOI: $\underline{10.5935 / 1984-6835.20140044}$
} 


\section{Agentes Vesicantes}

\section{Camilla G. Colasso, ${ }^{*}$ Tanos C. C. França}

Instituto Militar de Engenharia, Laboratório de Modelagem Aplicada à Defesa Química e Biológica (LMDQB), Praça General Tibúrcio 80, CEP 22290-270, Rio de Janeiro (RJ), Brasil.

* camillacolasso@gmail.com

Recebido em 15 de abril de 2014. Aceito para publicação em 15 de abril de 2014

\section{Introdução}

1.1. Aspectos históricos

1.2. Uso militar

\section{Propriedades físico-químicas}

2.1. Mostarda de enxofre

2.2. Mostardas nitrogenadas

2.3. Lewisita

2.4. Fosgênio oxima

\section{Toxicologia dos vesicantes}

3.1. Mecanismo de ação da mostarda

3.2. Mecanismo de ação da lewisita

3.3. Mecanismo de ação da fosgênio oxima

\section{Sinais e sintomas da intoxicação com vesicantes}

4.1. Intoxicação com mostardas

4.2. Intoxicação com Lewisita

4.3. Intoxicação com Fosgênio oxima

\section{Tratamento e descontaminação}

6. Considerações finais

\section{Introdução}

\subsection{Aspectos históricos}

Os agentes químicos de guerra são definidos como quaisquer substâncias químicas cujas propriedades tóxicas são utilizadas com a finalidade de matar, ferir ou incapacitar o inimigo na guerra ou em operações militares. ${ }^{1,2}$ Tais substâncias são empregadas pela humanidade desde tempos remotos, mas foi só a partir da I Guerra Mundial (GM) que ganharam a conotação de armas de destruição em massa, pois, devido à industrialização, puderam ser produzidas em 
grandes quantidades e ser amplamente usadas na guerra de trincheiras travada entre ingleses e franceses, de um lado, e alemães, do outro, causando milhares de baixas. ${ }^{3,4,5}$

O conceito de criar nuvens de gás tóxico em batalha foi creditado a Fritz Haber, do Instituto de Física de Berlim, em 1914. Devido à escassez de granadas, Haber pensou que uma nuvem de gás poderia incapacitar os combatentes inimigos sem a utilização de explosivos, com a vantagem de que o gás, ao se espalhar, poderia atingir uma área muito mais ampla que os ataques de artilharia., Em consequência dessa ideia ocorreu, em 17 de abril de 1915, o primeiro ataque alemão bem sucedido com gás cloro (selecionado para esse fim devido a sua abundância na indústria alemã) lançado nas trincheiras das tropas francesas em Ypres, Bélgica. ${ }^{7}$ Após o sucesso obtido pelos alemães em Ypres, teve início uma competição para a pesquisa e desenvolvimento de armas químicas mais potentes tanto pelos aliados como pela Alemanha. Em julho de 1917, os alemães introduziram o gás mostarda que, além de afetar o sistema respiratório, tem a capacidade de causar lesões em partes do corpo não protegidas. Assim, este tipo de agente não somente seria tóxico através da inalação como também através da pele. ${ }^{1,5} \mathrm{O}$ gás mostarda recebeu a denominação de "Rei dos Gases" na I GM, devido à eficácia dos ataques nos combates e aos danos provocados à saúde humana. Depois da I GM há relatos de emprego do gás mostarda pela Espanha em 1920, na Guerra do Rife, pela Itália contra a Etiópia em 1935 e 1936 (foi o primeiro ataque com armas químicas na forma de aerossol dispersado por aeronaves) e pelo Japão contra a China em 1938. . $^{1,10}$ Também há suspeitas de que o Egito o tenha empregado na guerra civil do lêmen, na década de 1960.1' O último uso militar registrado ocorreu na guerra Irã-Iraque (1980 a 1988) quando mais de cem mil iranianos sofreram injúrias devido à mostarda de enxofre e cerca de um terço deles ainda sofre os efeitos até hoje. ${ }^{12}$

A mostarda de enxofre recebeu o código CAS 505-60-2 pela Convenção para
Prevenção de Armas Químicas (CPAQ) ${ }^{13,14}$ e foi sintetizada pela primeira vez em 1822 por Despretz. $^{11,12,15}$ Em 1960, Niemenn e Guthrie evidenciaram suas propriedades vesicantes e, em 1886, Viktor Meyer sintetizou a mostarda de enxofre na forma mais purificada usando o processo de Levistein. ${ }^{11,12,15} \mathrm{Na}$ forma destilada a mostarda foi batizada como HD de acordo com o código militar dos EUA, designação que também é usada em países ocidentais. Outros nomes utilizados são: mostarda de enxofre (devido ao odor típico), iperita (porque foi usada pela primeira vez em Ypres, Bélgica), Lost (acrônimo dos nomes dos químicos alemães Lommel e Steinkopf que investigavam seu uso militar) e cruz amarela (porque cilindros contendo mostarda eram marcados com uma cruz amarela na primeira guerra). ${ }^{8} \mathrm{O}$ agente $\mathrm{T}$ (CAS 63918-89-8) tem ação similar à mostarda de enxofre. Uma mistura constituída por $40 \%$ de agente $\mathrm{T}$ e $60 \%$ de mostarda de enxofre (HD) é designada como HT. Além da mostarda de enxofre existem também as mostardas de nitrogênio - HN1 (CAS 538-07-8); HN2 (CAS 51-75-2) e HN3 (CAS 555-77-1). ${ }^{12,15,17}$

Embora o gás mostarda seja o mais emblemático, há outras substâncias com atividade vesicante, como a lewisita e a fosgênio oxima. A lewisita, ou 2clorovinildicloroarsina, foi sintetizada em 1903 e ganhou esse nome em 1918 quando a equipe sob as ordens do capitão Lewis, do Exército dos EUA, redescobriu seu potencial como arma química. ${ }^{6,17}$ O principal problema no uso da lewisita para esse fim é que ela sofre hidrólise rápida em condições úmidas, fato que diminui sua ação. A antiga União Soviética produziu uma mistura de gás mostarda com lewisita chamada HL. ${ }^{17}$ A lista de agentes químicos da CPAQ inclui dois tipos de lewisita: a bis-(2-clorovinil)cloroarsina (denominado L2) e a tris-(2-clorovinil) arsina (denominada L3). ${ }^{14}$

Um terceiro agente vesicante é conhecido como fosgênio oxima e recebeu o código $C X$, porém, diferente das mostardas e da lewisita, esse agente não produz bolhas. Após o contato com a pele ele provoca apenas 
urticárias e danos, mas algumas publicações também o consideram um vesicante. ${ }^{6}$

\subsection{Uso militar}

O primeiro emprego de gás mostarda ocorreu na I GM, no dia 12 de julho de 1917, quando tropas alemãs o lançaram contra tropas britânicas nas trincheiras em Ypres, Bélgica. Após alguns meses, ambos os lados estavam utilizando o gás mostarda que foi o responsável por $70 \%$ das vítimas de armas químicas durante a guerra. ${ }^{7,17,18,19}$ Os outros $30 \%$ foram vítimas, em sua maior parte de cloro e fosgênio. Mesmo tendo sido introduzido apenas no último ano da guerra a mostarda de enxofre foi responsável por 1,3 milhões de baixas. ${ }^{18,19} \mathrm{~A}$ comparação com os 5 milhões provocados por armas convencionais durante toda a guerra ilustra o potencial da mostarda como arma de destruição em massa. Dos 180.983 soldados britânicos vítimas das armas químicas, 160.970 (88\%) o foram unicamente pelo gás mostarda sendo que 4.167 (2,6\%) foram vítimas fatais. Dos 36.765 soldados norteamericanos vítimas das armas químicas, 27.711 (75\%) o foram unicamente pelo gás mostarda. A taxa da mortalidade devida às lesões provocadas pelo gás mostarda na I GM foi de $7 \%{ }^{10}$ Os sobreviventes tiveram de receber tratamento médico por um longo período. A combinação de longos períodos de repouso e elevado número de vítimas, ilustra a eficácia do gás mostarda como agente de guerra.

Durante a guerra Irã-Iraque (1980 - 1988) estima-se que 45 mil pessoas foram vítimas do gás mostarda. ${ }^{18,19}$ Inspeções da Organização das Nações Unidas (ONU) nos campos de batalha daquela guerra, realizadas em 1984, 1986 e 1987, para investigar o emprego de armas químicas concluíram que foram empregados mostarda de enxofre e o agente neurotóxico tabun. ${ }^{11}$

A lewisita foi produzida em grandes quantidades pelos EUA durante a I GM, porém não foi utilizada. Todavia há relatos de que o Japão a tenha empregado contra a China entre 1937 e $1944 .^{11}$

A fosgênio oxima foi primeiro sintetizada por cientistas alemães em 1929 e depois pela Rússia. Todavia ambos os países não tinham ideia do potencial desse agente como arma química. ${ }^{6}$ Os EUA também estudaram a fosgênio oxima antes da II GM, porém a rejeitaram por acharem que os efeitos biológicos não eram satisfatórios e devido à instabilidade química. ${ }^{6}$ A aparente ausência de efeitos biológicos foi mais tarde pesquisada em estudos pré II GM que evidenciaram que a fosgênio oxima apresentava efeitos nocivos em baixas concentrações (1 - 2\%). O interesse inicial na fosgênio oxima como agente de guerra veio de sua capacidade de penetração em roupas de borracha, muito mais rápida do que a de outros agentes, e da produção rápida de efeitos graves e prolongados à saúde humana. Quando misturada com outro agente químico (ex.: VX), a fosgênio oxima produz rapidamente danos à pele tornando-a mais susceptível à penetração do segundo agente. $^{9}$

\section{Propriedades físico-químicas}

\subsection{Mostarda de enxofre}

Embora frequentemente chamado de "gás mostarda", esse agente é líquido a temperatura ambiente, porém se dispersa rapidamente em temperaturas altas e umidade baixa. ${ }^{8,9,11}$ Devido à consistência oleosa e baixa solubilidade em água, a mostarda de enxofre é persistente no meio ambiente. As impurezas the conferem um odor característico de alho ou mostarda que, junto com a coloração de amarelo a castanho escuro, lhe rendeu o nome de mostarda na I GM. As vias de penetração da mostarda de enxofre in vitro $\left(71-294 \mu \mathrm{g} \cdot \mathrm{cm}^{-2} \cdot \mathrm{h}^{-1}\right.$, pele humana) e in vivo com voluntários humanos $\left(60-240 \mu \mathrm{g} \cdot \mathrm{cm}^{-2} \cdot \mathrm{h}^{-1}\right)$ são similares. ${ }^{20} \mathrm{~A}$ 
concentração de mostarda líquida sobre a pele necessária para a ação vesicante é de 20 $\mu \mathrm{g} . \mathrm{cm}^{-2}$. Em contraste apenas $4 \mu \mathrm{g} . \mathrm{cm}^{-2}$ de vapor da mostarda de enxofre são necessários para produzir as bolhas. Essa aparente discrepância pode ser explicada pela taxa de evaporação do líquido de $80 \%$ antes de penetrar na pele. Portanto, condições de calor aumentam a penetração na pele e potencializam os efeitos tóxicos. ${ }^{20}$ O nome químico, sinônimos, código de identificação, fórmula e estrutura química da mostarda de enxofre estão descritos na Tabela 1.

Tabela 1. Nomenclatura, fórmula e estrutura química da mostarda de enxofre. ${ }^{17,20}$

\begin{tabular}{|c|c|}
\hline \multicolumn{2}{|c|}{ Mostarda de enxofre (HD) } \\
\hline Sinônimos & $\begin{array}{l}\text { bis(2-cloroetil)sulfato; 1-cloro-2-(2- } \\
\text { cloroetiltio)etano; gás mostarda, iperita; cruz } \\
\text { amarela; agente HD; mostarda destilada; }\end{array}$ \\
\hline $\mathrm{N}^{\circ} \mathrm{CAS}$ & $506-60-2$ \\
\hline Fórmula química & $\mathrm{C}_{4} \mathrm{H}_{8} \mathrm{Cl}_{2} \mathrm{~S}$ \\
\hline $\begin{array}{c}\mathrm{PE}\left({ }^{\circ} \mathrm{C}\right) ; \mathrm{PF}\left({ }^{\circ} \mathrm{C}\right) ; \mathrm{LC}_{\mathrm{t}} 50 \\
\left(\mathrm{mg} \cdot \mathrm{min} \cdot \mathrm{m}^{-3}\right)\end{array}$ & $215 ; 14,5 ; 1500$ \\
\hline Densidade do líquido $\left(\mathrm{g} \cdot \mathrm{cm}^{-3}\right)$ & 1,27 \\
\hline Densidade do vapor $(a r=1)$ & 5,4 \\
\hline Volatilidade $\left(\mathrm{mg} \cdot \mathrm{m}^{-3}\right)$ & $610\left(20^{\circ} \mathrm{C}\right)$ \\
\hline Estrutura química & \\
\hline
\end{tabular}

\subsection{Mostardas nitrogenadas}

Os nomes químicos, sinônimos, códigos de identificação e fórmulas estruturais das mostardas nitrogenadas estão na Tabela 2. Elas são bis(2-cloroetil)-aminas terciárias com odor de peixe e atividades vesicante e alquilante. ${ }^{17}$ Devido às propriedades tóxicas e às características físico-químicas as mostardas nitrogenadas tiveram interesse inicialmente como agentes químicos de guerra, um pouco antes e durante a II GM. HN2 e HN3 foram desenvolvidas como armas químicas, já a HN1 foi originalmente desenvolvida como medicamento. Posteriormente a HN2 foi empregada como agente neoplásico sob o nome mustargen ${ }^{\circledR}$. As mostardas nitrogenadas e compostos derivados como ciclofosfamida, clorambucil e melfalano são agentes alquilantes utilizados no tratamento do câncer. ${ }^{8,9,11,12}$

Tabela 2. Nomenclatura e fórmula química das mostardas nitrogenadas ${ }^{8,9,11,12}$

\begin{tabular}{|c|c|}
\hline \multicolumn{2}{|r|}{ HN1 } \\
\hline Sinônimos & Etil-bis(2-cloroetil)amina; bis-(2-cloroetil) etilamina \\
\hline $\mathrm{N}^{\circ} \mathrm{CAS}$ & $538-078$ \\
\hline $\begin{array}{c}\mathrm{PE}\left({ }^{\circ} \mathrm{C}\right) ; \mathrm{PF}\left({ }^{\circ} \mathrm{C}\right) ; \mathrm{LC}_{\mathrm{t}} 50 \\
\left(\mathrm{mg} \cdot \mathrm{min} \cdot \mathrm{m}^{-3}\right)\end{array}$ & 194 (decomposição); -34; 1500 \\
\hline
\end{tabular}




$$
\begin{aligned}
& \text { Densidade do líquido }\left(\mathrm{g} \cdot \mathrm{cm}^{-3}\right) \\
& \text { Densidade do vapor }(\mathrm{ar}=1) \\
& \text { Volatilidade }\left(\mathrm{mg} \cdot \mathrm{m}^{-3}\right)
\end{aligned}
$$

Estrutura
1,09

5,9

$1520\left(20^{\circ} \mathrm{C}\right)$<smiles>CCN(CCCl)CCCl</smiles>

\section{HN2}

Sinônimos

$N^{\circ}$ CAS

PE $\left({ }^{\circ} \mathrm{C}\right) ; \operatorname{PF}\left({ }^{\circ} \mathrm{C}\right) ; \mathrm{LC}_{\mathrm{t}} 50$

(mg.min. ${ }^{-3}$ )

Densidade do líquido $\left(\mathrm{g} . \mathrm{cm}^{-3}\right)$

Densidade do vapor $(\operatorname{ar}=1)$

Volatilidade $\left(\mathrm{mg} \cdot \mathrm{m}^{-3}\right)$

Estrutura
Metil-bis(cloroetil) amina; 2,2'-dicloro- $N$-metildietilamina; "s"; mecloroetamina

$$
\text { 51-75-2 }
$$

$75 ;-65 ; 3000$

1,15

5,4

$3580\left(25^{\circ} \mathrm{C}\right)$<smiles>CN(CCCl)CCCl</smiles>

HN3

Sinônimos

$\mathrm{N}^{\circ}$ CAS

$\operatorname{PE}\left({ }^{\circ} \mathrm{C}\right) ; \operatorname{PF}\left({ }^{\circ} \mathrm{C}\right) ; \mathrm{LC}$ t50

(mg.min. ${ }^{-3}$ )

Densidade do líquido $\left(\mathrm{g} . \mathrm{cm}^{-3}\right)$

Densidade do vapor $(\operatorname{ar}=1)$

Volatilidade (mg. $\left.\mathrm{m}^{-3}\right)$

Estrutura
Tris(cloroetil)amina; tris(2-cloroetil)amina hidrocloreto

555-77-1

256 (decomposição); -3,7; 1500

1,24

7,1

$121\left(25^{\circ} \mathrm{C}\right)$<smiles>ClCCN(CCCl)CCCl</smiles>

\subsection{Lewisita}

A lewisita ( $\beta$-clorovinildicloroarsina) é um composto arsenical com importância secundária dentre os vesicantes. Foi sintetizado no início do século $X X$ e tem pouco emprego nos campos de batalha. Ela é semelhante às mostardas em termos de toxicidade e provoca danos à pele, aos olhos e às vias respiratórias, porém, difere das mostardas porque seus efeitos clínicos aparecem rapidamente após a exposição. ${ }^{6} \mathrm{~A}$ lewisita é formada pelos isômeros cis e trans da $\beta$-clorovinildicloroarsina (L1) em uma 
relação 1:9 e várias impurezas incluindo a bis(2-clorovinil)cloroarsina (L2) e a tris(2clorovinil)arsina (L3). Na forma pura é incolor, mas normalmente ocorre na forma líquida oleosa marrom com odor característico de gerânios. ${ }^{11}$ Os nomes químicos, sinônimos, códigos de identificação, fórmulas químicas e estruturas das lewisitas L1, L2 e L3 estão na Tabela 3.
Em climas frios, a lewisita é mais volátil e mais persistente do que as mostardas e se mantém na forma líquida mesmo em temperaturas baixas, o que a torna um composto perfeito para dispersão em climas frios. Todavia sofre rápida hidrólise em climas úmidos, o que diminui sua atividade biológica. ${ }^{11}$

Tabela 3. Nomenclatura, fórmulas e estruturas químicas das lewisitas ${ }^{8,9,11,12}$

\begin{tabular}{|c|c|}
\hline \multicolumn{2}{|r|}{ Lewisita (L1) } \\
\hline Sinônimos & $\begin{array}{l}\text { 2-clorovinildicloroarsina; (2-clorovinil)dicloroarsina; beta- } \\
\text { clorovinildicloroarina; dicloro(2-clorovinil) arsina; } \\
\text { dicloroclorovinilarsina; EA } 1034\end{array}$ \\
\hline $\mathrm{N}^{\circ} \mathrm{CAS}$ & $541-25-3$ \\
\hline Fórmula química & $\mathrm{ClCH}=\mathrm{CHAsCl}_{2}$ \\
\hline $\begin{array}{c}\mathrm{PE}\left({ }^{\circ} \mathrm{C}\right) ; \mathrm{PF}\left({ }^{\circ} \mathrm{C}\right) ; \mathrm{LC}_{\mathrm{t}} 50 \\
\left(\mathrm{mg} \cdot \mathrm{min} \cdot \mathrm{m}^{-3}\right)\end{array}$ & $190 ;-18 ; 1200-1500$ \\
\hline Densidade do líquido $\left(\mathrm{g} \cdot \mathrm{cm}^{-3}\right)$ & $1,89\left(20^{\circ} \mathrm{C}\right)$ \\
\hline Densidade do vapor $(a r=1)$ & 7,1 \\
\hline Volatilidade $\left(\mathrm{mg} \cdot \mathrm{m}^{-3}\right)$ & $4480\left(20^{\circ} \mathrm{C}\right)$ \\
\hline Estrutura química & $\mathrm{AsCl}_{2}$ \\
\hline \multicolumn{2}{|r|}{ L2 } \\
\hline Sinônimos & Lewisita 2 \\
\hline $\mathrm{N}^{\circ} \mathrm{CAS}$ & $40334-69-8$ \\
\hline Fórmula química & $(\mathrm{ClCH}=\mathrm{CH})_{2} \mathrm{AsCl}$ \\
\hline $\begin{array}{c}\mathrm{PE}\left({ }^{\circ} \mathrm{C}\right) ; \mathrm{PF}\left({ }^{\circ} \mathrm{C}\right) ; \mathrm{LC}_{\mathrm{t}} 50 \\
\left(\mathrm{mg} \cdot \mathrm{min} \cdot \mathrm{m}^{-3}\right)\end{array}$ & --- \\
\hline Densidade do líquido $\left(\mathrm{g} \cdot \mathrm{cm}^{-3}\right)$ & --- \\
\hline Densidade do vapor $(a r=1)$ & --- \\
\hline Volatilidade $\left(\mathrm{mg} \cdot \mathrm{m}^{-3}\right)$ & --- \\
\hline Estrutura química & $\underset{\mathrm{Cl}}{\mathrm{Cl}}$ \\
\hline \multicolumn{2}{|r|}{ L3 } \\
\hline Sinônimos & Lewisita 3 \\
\hline $\mathrm{N}^{\circ} \mathrm{CAS}$ & 40334-70-1 \\
\hline
\end{tabular}


Fórmula química

$\operatorname{PE}\left({ }^{\circ} \mathrm{C}\right) ; \operatorname{PF}\left({ }^{\circ} \mathrm{C}\right) ; \mathrm{LC}_{\mathrm{t}} 50$

(mg.min. $\mathrm{m}^{-3}$ )

Densidade do líquido $\left(\mathrm{g} . \mathrm{cm}^{-3}\right)$

Densidade do vapor $(\operatorname{ar}=1)$

Volatilidade (mg. $\mathrm{m}^{-3}$ )

Estrutura química
$(\mathrm{ClCH}=\mathrm{CH})_{3} \mathrm{As}$

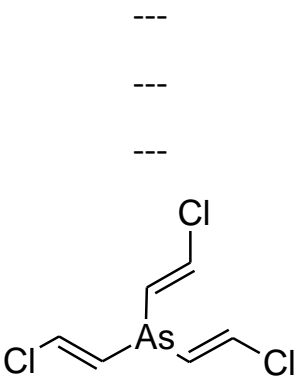

\subsection{Fosgênio oxima}

A fosgênio oxima não é um vesicante verdadeiro porque não produz bolhas. Esse composto provoca urticária, eritema e pápulas. É considerado um agente corrosivo e provoca sérios danos aos tecidos. Não há relatos do emprego da fosgênio oxima em campo de batalha e há poucas informações sobre seus efeitos em seres humanos. ${ }^{11} \mathrm{~A}$ fosgênio oxima na forma pura (dicloroformoxima) é um sólido com ponto de fusão entre 35 e $40^{\circ} \mathrm{C}$ e a forma usada para munição é um líquido de coloração amarelo-castanha. ${ }^{8}$ o nome químico, sinônimos, código de identificação, fórmula química e estrutura da fosgênio oxima estão na Tabela 4.

Tabela 4. Nomenclatura, fórmula e estrutura química do fosgênio oxima ${ }^{11}$

\begin{tabular}{|c|c|}
\hline \multicolumn{2}{|r|}{ Fosgênio oxima (CX) } \\
\hline Sinônimos & $\begin{array}{l}\text { CX; oxima dicloroformaldeído; dicloroformaldoxima; } \\
\text { dicloroformossina; dicloroformoxima }\end{array}$ \\
\hline $\mathrm{N}^{\circ} \mathrm{CAS}$ & $1794-86-1$ \\
\hline Fórmula molecular & $\mathrm{CHCl}_{2} \mathrm{NO}$ \\
\hline $\begin{array}{l}\mathrm{PE}\left({ }^{\circ} \mathrm{C}\right) ; \mathrm{PF}\left({ }^{\circ} \mathrm{C}\right) ; \mathrm{LC}_{\mathrm{t}} 50 \\
\left(\mathrm{mg} \cdot \mathrm{min} \cdot \mathrm{m}^{-3}\right)\end{array}$ & 128; ---; --- \\
\hline Densidade do líquido $\left(\mathrm{g} \cdot \mathrm{cm}^{-3}\right)$ & --- \\
\hline Densidade do vapor $(a r=1)$ & $<3,9$ \\
\hline Volatilidade $\left(\mathrm{mg} \cdot \mathrm{m}^{-3}\right)$ & $1800\left(20^{\circ} \mathrm{C}\right)$ \\
\hline Estrutura química & $\mathrm{N}^{-\mathrm{OH}}$ \\
\hline
\end{tabular}

\section{Toxicologia dos vesicantes}

\subsection{Mecanismo de ação da mostarda}

O mecanismo de ação das mostardas é pesquisado há anos. Inicialmente, as pesquisas sugeriram que a mostarda era hidrolisada no interior das células e formava ácido clorídrico, porém outros estudos mostraram que a ação vesicante não estava relacionada com a liberação de ácido. ${ }^{12}$ Novos estudos evidenciaram que a ação tóxica da mostarda estava relacionada à reações com proteínas e enzimas, especialmente a reação com a hexoquinase 
que passou a ser considerada uma das alterações bioquímicas mais importantes relacionadas às mostardas. As teorias que foram propostas incluem a depleção da glutationa e, ainda, a peroxidação lipídica. ${ }^{12}$ Estas teorias, porém, ainda não estão de acordo com o padrão de danos provocados pela exposição à mostarda. No entanto, algumas das mudanças bioquímicas que levaram a estas teorias são reconhecidas como componentes da teoria atual proposta para a citotoxicidade da mostarda de enxofre. ${ }^{12}$

A teoria hoje mais aceita para definir o mecanismo de ação tóxica das mostardas (de enxofre e nitrogenadas) correlaciona-se à reação de alquilação dos constituintes celulares, principalmente, DNA, RNA, proteínas e membranas lipídicas. Essas reações podem resultar em alterações das funções fisiológicas, metabólicas e genéticas das células. Supõe-se que a mostarda sofra uma primeira reação com a cadeia 2-cloroetil sofrendo uma ciclização intramolecular para gerar o íon ônio (sulfônio ou imônio) e, logo após, o íon carbênio (Figura 1). 0 íon carbênio reage com o DNA (especificamente com a N7-Guanina), RNA, proteínas e outras moléculas conforme ilustrado nas Figuras $1 \mathrm{e}$ 2. Após a exposição, as células tentam reparar o DNA danificado e recuperá-lo. Caso isso não seja possível ocorre a morte celular, que no caso dos queratinócitos (células do tecido epitelial) pode ser por apoptose, necrose ou diferenciação terminal. ${ }^{12}$

O núcleo celular parece ser o componente mais sensível à ação da mostarda de enxofre. As reações mais importantes ocorrem com o
DNA, onde a 7-(2-hidroxietil) guanina (7-HEG) sofre $61 \%$ do total da alquilação. Outras alquilações ocorrem na posição 3 da adenina (16\%) e na posição 6 da guanina $(0,1 \%)$. Presume-se que os efeitos mutagênicos da mostarda de enxofre sejam em parte pela deformação da 06-(2-etiltioetil)guanina. Quase $17 \%$ do total de alquilações envolve 2 guaninas (G-alquilguanina) na mesma fita ou na fita oposta do DNA. ${ }^{12}$

Há evidências de que um ponto crítico no mecanismo de ação das mostardas é a ativação da enzima Poli[ADPribose]polimerase 1 (PARP-1). ${ }^{12}$ Os danos provocados pela mostarda no DNA ativam a PARP-1 e resultam na depleção da produção de seu substrato, a nicotinamida adenina dinucleotídeo $\left(\mathrm{NAD}^{+}\right)$. A diminuição da produção de $\mathrm{NAD}^{+}$auxilia na inibição da glicólise, o que leva à geração de excesso de energia na célula na forma de adenosinatrifosfato (ATP). ${ }^{12}$ A perda intracelular desse ATP provoca morte celular por necrose. A preservação de níveis de $\mathrm{NAD}^{+}$para prevenir a ativação da PARP-1 e impedir a morte celular só ocorre nas primeiras horas após a lesão. Porém, a inibição da PARP-1 também bloqueia a reparação do DNA. Assim, a degradação do DNA provoca a morte celular por apoptose. Na fase inicial da apoptose, a PARP-1 torna-se substrato para a caspase-3. Os estímulos apoptóticos provocam uma explosão na formação de adenosina difosfato ribose (ADP-ribose), porém, a PARP-1 cliva e inibe a atividade da ADP-ribose para o consumo de energia. Além disso, ocorre a ativação de várias proteases e citocinas próinflamatórias no processo. ${ }^{12}$ 


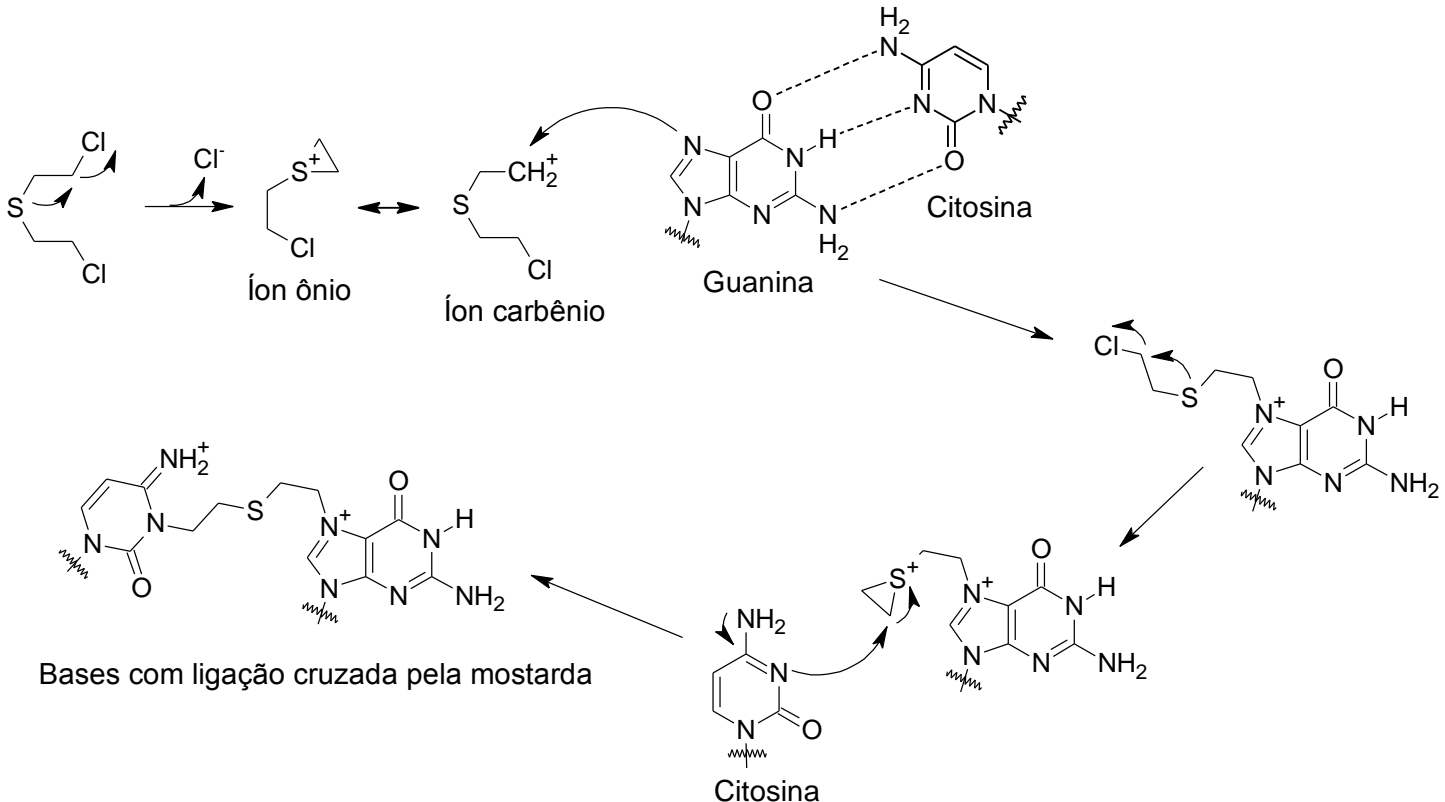

Figura 1. Formação dos íons ônio e carbênio e reações da mostarda de enxofre com bases do DNA ${ }^{12}$

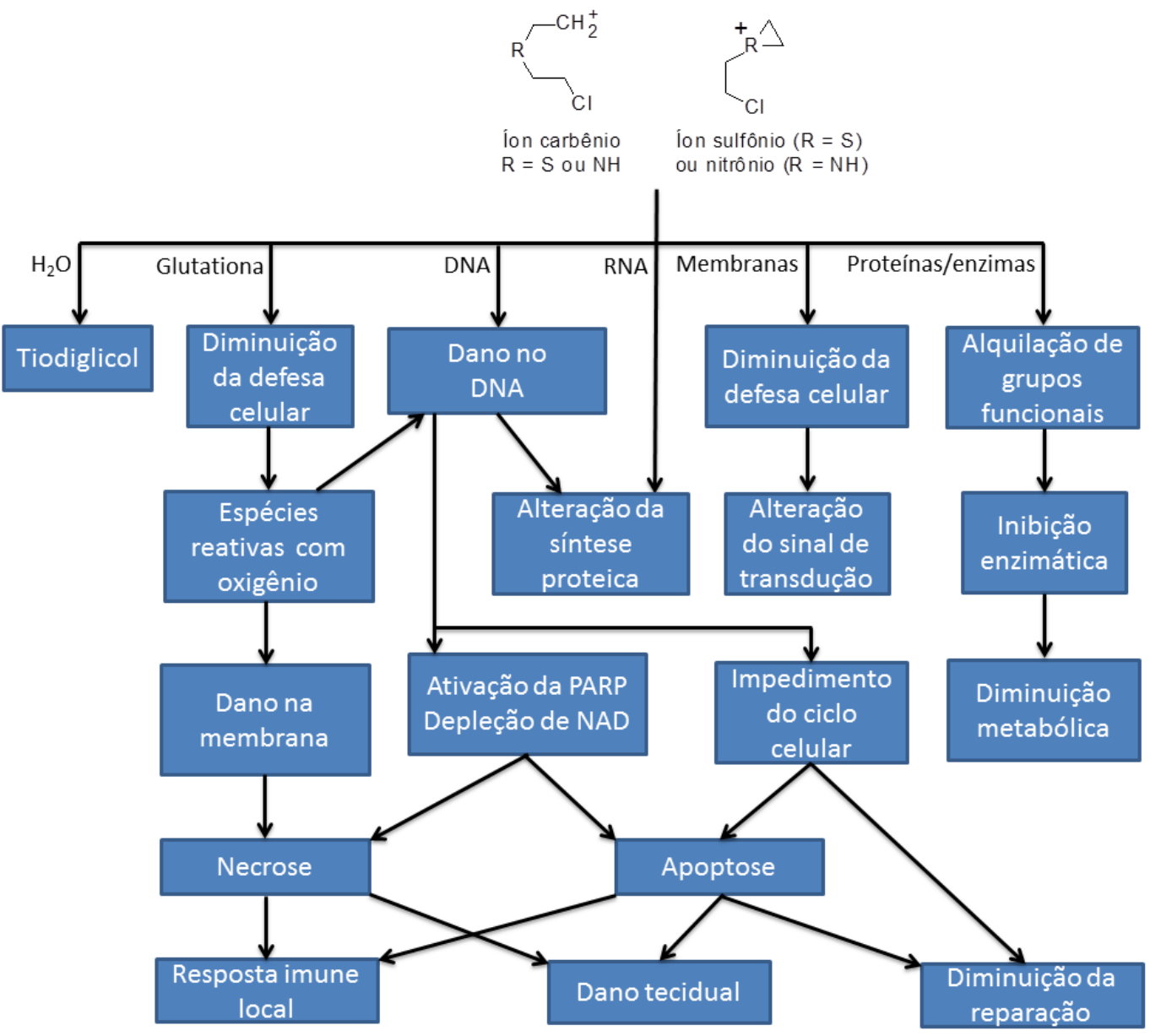

Figura 2. Reações da mostarda de enxofre com diferentes moléculas. Após a formação dos íons intermediários (sulfônio e carbônio) os mesmos podem reagir com água, DNA, RNA, proteínas e enzimas. Diversas funções celulares são alteradas, e em consequência, ocorre a morte celular (apoptose, necrose $)^{12}$ 


\subsection{Mecanismo de ação da lewisita}

Supõe-se que a ação tóxico da lewisita (Figura 3) seja devido à presença do átomo de Arsênio trivalente $\left(\mathrm{As}^{+3}\right)$ na estrutura, que seria o responsável pela ação vesicante e a toxicidade sistêmica desse agente. A solubilidade lipídica da lewisita faz com que, após o contato com o composto, o $\mathrm{As}^{+3}$ seja prontamente absorvido pela pele, exercendo sua ação sistêmica e provocando o desenvolvimento das vesicações dolororas $^{11,22} \mathrm{O} \mathrm{As}^{+3}$ é capaz de se ligar a proteínas contendo sulfidrila, especialmente enzimas, inibindo, assim, a oxidação do piruvato, que é uma reação crítica no metabolismo dos carboidratos. $O$ seu mecanismo de ação baseia-se na inibição do complexo piruvato-desidrogenase, que compreende três enzimas, a partir da ligação do $\mathrm{As}^{+3}$ aos grupamentos sulfidrila da dihidrolipoamida. ${ }^{21,22}$ Assim, se impede a regeneração da lipoamida, que é um cofator necessário à conversão do piruvato em acetil coenzima A (acetilCoA). A redução da concentração de acetilCoA provoca a queda nos níveis de ATP que irá afetar diversas funções celulares dependentes do consumo de energia. ${ }^{21} \mathrm{O} \mathrm{As}^{+3}$ também inibe as enzimas glutationa sintetase, glicose 6-fosfato desidrogenase (G6PD) e a glutationa redutase, reduzindo os níveis de glutationa disponíveis, que, por sua vez, são necessários para o processo de biotransformação do próprio $\mathrm{As}^{+3}$ no fígado. ${ }^{21,22}$

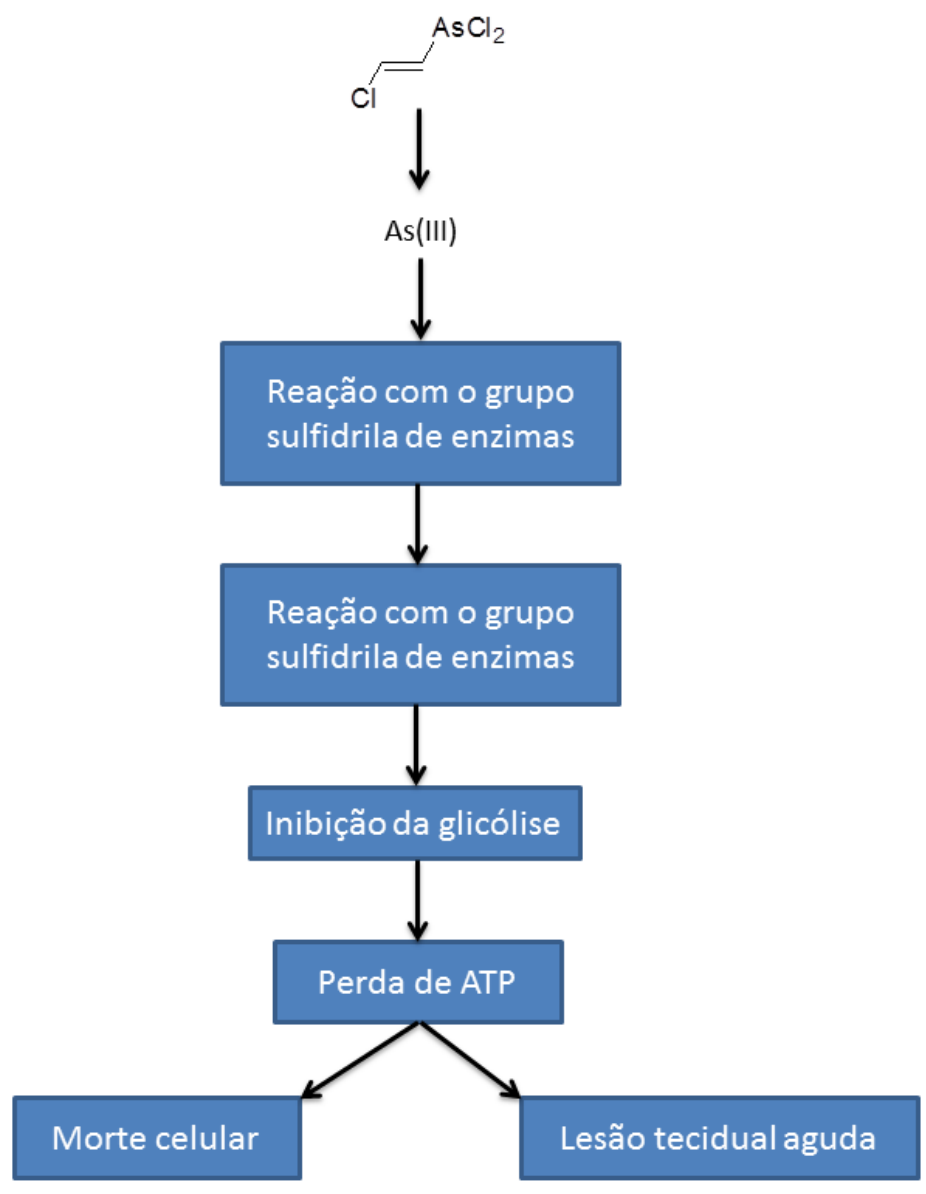

Figura 3. Mecanismo de ação do $\mathrm{As}^{+3}$ oriundo da lewisita ${ }^{11}$

3.3. Mecanismo de ação da fosgênio oxima
O mecanismo de ação tóxico da fosgênio oxima ainda é desconhecido. Sabe-se que esse agente pode provocar efeito necrosante 
por causa do cloro, por ação direta da oxima, ou por causa do grupo carbonila. ${ }^{11}$ As lesões cutâneas provocadas por ela são semelhantes às de um ácido forte e os seus efeitos sistêmicos mostram primeira ação no leito capilar onde ela se encontra. Segundo Mc Adams e Joffe ${ }^{11}$ a injeção intravenosa e aplicação cutânea da fosgênio oxima provoca edema pulmonar. Porém, a injeção na veia porta produz necrose hepática, mas não produz edema pulmonar. Os prováveis mecanismos de ação da fosgênio oxima estão esquematizados na Figura 4.

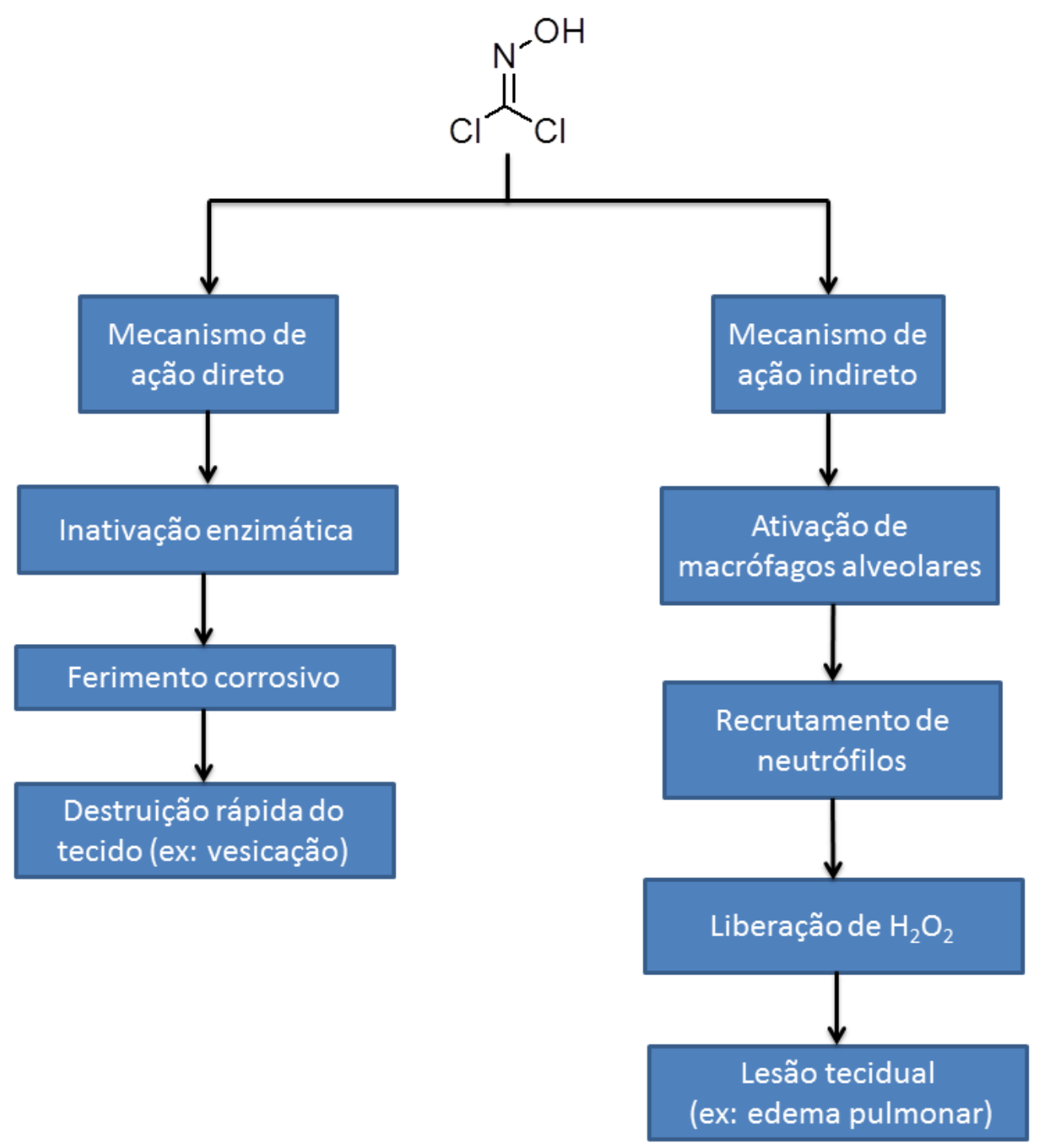

Figura 4. Possíveis mecanismos de ação do fosgênio oxima ${ }^{11}$

\section{Sinais e sintomas da intoxicação com vesicantes}

\subsection{Intoxicação por mostarda}

Os órgãos mais afetados pelo gás mostarda são os que entram em contato direto com o agente: pele, olhos e sistema respiratório. Após a absorção da mostarda por via dérmica ou inalatória, o sistema hematopoiético, o trato gastrointestinal e o sistema nervoso central (SNC) são 
afetados. ${ }^{9,11}$ Durante a I GM, 80 a $90 \%$ das baixas do exército norte americano tiveram lesões de pele provocadas pela mostarda, $86 \%$ tiveram danos oculares e $75 \%$ tiveram danos nas vias respiratórias. Tais valores são muito semelhantes às baixas iranianas na guerra Irã-Iraque. ${ }^{12}$

A quantidade de vapor necessária para produzir lesões na pele (eritema) é de cerca de $200 \mathrm{mg} \cdot \mathrm{min} \cdot \mathrm{m}^{-3}$. Porém, ela depende de alguns fatores, como temperatura, umidade, hidratação da pele e região do corpo atingida. Regiões quentes e úmidas tais como o períneo, a genitália externa, as axilas, a fossa antecubital e o pescoço são as áreas mais sensíveis. Uma gota de mostarda (10 $\mu \mathrm{g})$ sobre a pele é suficiente para provocar a vesicação. Cerca de $80 \%$ do líquido evapora e $10 \%$ são absorvidos e penetram na circulação, os outros $10 \%$ ficam na superfície da pele e provocam a lesão tópica.

O vapor de mostarda penetra na pele na dose de $1,4 \mu \mathrm{g} \cdot \mathrm{cm}^{-2} \cdot \mathrm{min}^{-1}$ em $21,1^{\circ} \mathrm{C}$ e de 2,7 $\mu \mathrm{g} . \mathrm{cm}^{-2} \cdot \mathrm{min}^{-1}$ em $31,1^{\circ} \mathrm{C}$. A mostarda líquida penetra na pele na dose de $2,2 \mu \mathrm{g} \cdot \mathrm{cm}^{-2} \cdot \mathrm{min}^{-1}$ em $15,6^{\circ} \mathrm{C}$ e na dose de $5,5 \mu \mathrm{g} \cdot \mathrm{cm}^{-2} \cdot \mathrm{min}^{-1} \mathrm{em}$ $38,9^{\circ} \mathrm{C}$. Isso faz com que o efeito da exposição à mostarda líquida manifeste-se mais rapidamente do que os efeitos da exposição ao vapor do gás mostarda. ${ }^{9,12} \mathrm{~A}$ forma mais branda de lesão causada pelo gás mostarda é o eritema visível que se assemelha à queimadura solar. 0 eritema começa a aparecer de 1 a 24 horas após a exposição, acompanhado de prurido (coceira) e ardor. Em casos de exposição a baixas concentrações, a lesão não passa disso, mas em concentrações mais elevadas, desenvolvem-se vesículas na periferia das áreas eritematosas (como um colar de pérolas). Essas vesículas se aglutinam mais tarde e formam bolhas maiores. Normalmente, o aparecimento do eritema ocorre em torno de 4 a 8 horas após a exposição e a vesicação ocorre entre 2 e 18 horas após a exposição. A vesicação característica da intoxicação por mostarda (Figura 5) é uma bolha grande em forma de cúpula, translúcida, com paredes finas, superficial, amarelada e rodeada por eritema, podendo ter até $5 \mathrm{~cm}$ de diâmetro ou largura. ${ }^{11,12} \mathrm{O}$ fluido das bolhas tem inicialmente coloração clara ou ligeiramente cor de palha e, depois de algum tempo, tende a tornar-se amarelado e a coagular. Esse fluido é rico em tioglicol, não contém mostarda e por si só não é um vesicante. A presença do tiodiglicol é usada como indicativo de intoxicação por mostarda. ${ }^{11,12,17}$
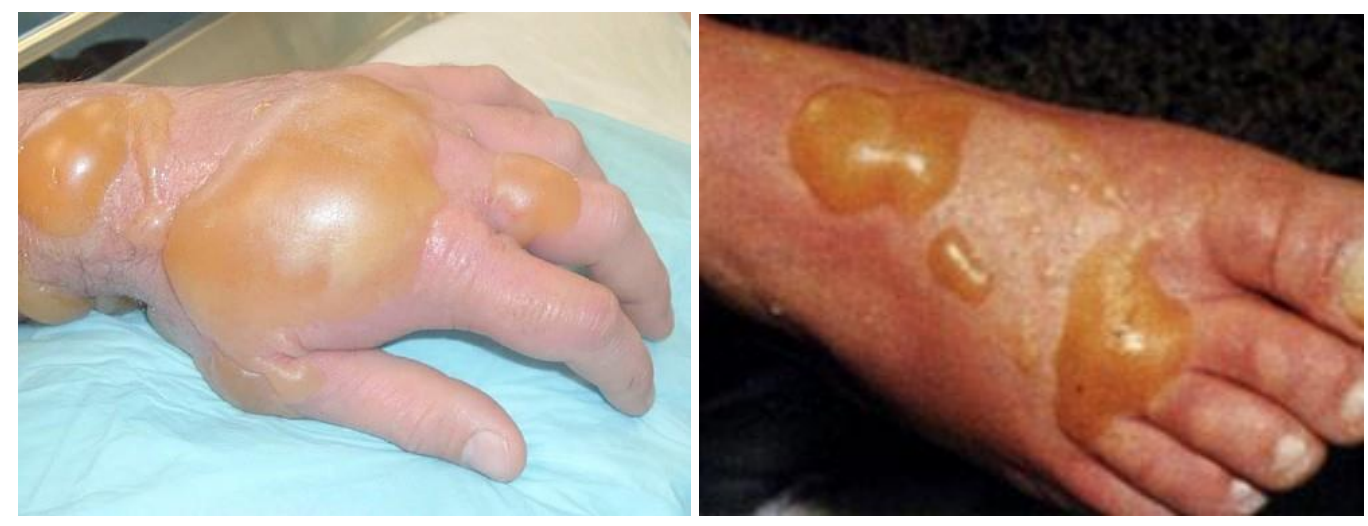

Figura 5. Vesicação característica da ação das mostardas. Adaptado de http://imgarcade.com/1/mustard-gas-canister/ e http://manbironline.com/diseases/mustard.htm

Os danos provocados pela exposição ao vapor de mostarda assemelham-se a queimaduras de primeiro e segundo grau, já a exposição à mostarda líquida produz lesões semelhantes a queimaduras de terceiro grau. A exposição a doses elevadas de mostarda, 
principalmente na forma líquida, produz lesões caracterizadas por uma zona central necrosada e leva à formação de bolhas na periferia. Essas lesões são as mais graves, demandam um período maior para a recuperação e são as mais propensas a infecções. ${ }^{11}$

As glândulas sudoríparas e sebáceas também são importantes vias de entrada para a mostarda e para acesso a camadas mais profundas da pele. Entretanto, a epitelização da pele após a exposição é frequentemente observada a partir de queratinócitos do folículo piloso, que são um importante reservatório de células-tronco da pele. $^{11}$

Outro fenômeno importante é o escurecimento da pele após a exposição. A pigmentação marrom escura pode persistir por décadas na área afetada. Em contraste, pode acontecer também a hipopigmentação. A poiquilodermia (hiperpigmentação) também é um efeito tardio característico da exposição à mostarda de enxofre. ${ }^{11,12,17}$

Os olhos são os órgãos externos mais sensíveis ao gás mostarda. O período de latência para $o$ aparecimento dos danos oculares é mais curto se comparado com o aparecimento dos danos à pele (Tabela 5). Geralmente, o período assintomático varia de acordo com a concentração do vapor de mostarda e com a sensibilidade individual. Há relatos de que a irritação ocular aparece minutos após a exposição. ${ }^{11} \mathrm{~A}$ exposição à baixas concentrações provoca ligeira irritação e vermelhidão. Com o aumento da concentração desenvolvem-se a conjuntivite, o blefaroespasmo, dores e danos na córnea. O desenvolvimento de fotofobia ocorre em casos de exposição a concentrações moderadas e pode permanecer por semanas. ${ }^{17}$ Os danos na córnea incluem a formação de edemas com turvação, inchaço e infiltração de células polimorfonucleares. A melhora clínica ocorre após sete dias, com a diminuição do edema. A vascularização da córnea (pannus) com edema secundário pode levar semanas e a visão pode ser perdida se o pannus afetar o eixo visual. Os efeitos graves da exposição à mostarda são a formação de cicatrizes entre a íris e o cristalino, que restringem os movimentos da pupila predispondo ao desenvolvimento de glaucoma. ${ }^{12} \mathrm{O}$ dano ocular mais grave é provocado pela exposição à mostarda na forma líquida. Os sintomas aparecem minutos após a exposição e são evidentes, com lesões na córnea e possível perfuração. Pode ocorrer a perda da visão ou até do globo ocular, devido ao desenvolvimento de panoftalmite, principalmente se os olhos forem tapados, pois a drenagem da infecção fica impedida. Pode também ocorrer miose, devido à atividade colinérgica da mostarda. ${ }^{12}$

Durante a I GM, o gás mostarda foi responsável por $75 \%$ das lesões oculares moderadas e a recuperação completa dessas lesões demorava de 1 a 2 semanas. Severa conjuntivite com mínimo envolvimento da córnea, blefaroespasmo, edema das pálpebras e conjuntiva e rugosidade da córnea foi observada em $15 \%$ dos casos cuja recuperação levava em torno de 2 a 5 semanas. ${ }^{11,17}$ Casos de envolvimento moderado da córnea com erosão em áreas da córnea, cicatrização da córnea, vascularização e irite, foram contabilizados em $10 \%$ dos casos e o período de recuperação levava em torno de 2 a 3 meses. ${ }^{11,17}$ Casos mais graves, com comprometimento da córnea, necrose isquêmica da conjuntiva, opacidade da córnea, ulceração profunda e vascularização representaram $0,1 \%$ dos casos e o período de recuperação levava mais de 3 meses. ${ }^{12}$ Inicialmente a mostarda provoca vasodilatação e aumento da permeabilidade vascular na conjuntiva, que leva ao desenvolvimento de edema. A secreção de muco ocorre minutos após a exposição, com picnose das células epiteliais logo após ou simultaneamente às alterações descritas, e descamação do epitélio. Nos estágios mais avançados, ocorrem infiltrado inflamatório do tecido conjuntivo e exsudação. ${ }^{9,11} \mathrm{Na}$ dose limiar (vapor: 50 - 100 mg.min.m ${ }^{-3}$ ) os sintomas oculares são: conjuntivite, arenosidade nas pálpebras e lacrimejamento. Esses sintomas ocorrem, geralmente, entre 
4-12 horas após a exposição. Doses mais elevadas (vapor: > $\left.200 \mathrm{mg} \cdot \mathrm{min} \cdot \mathrm{m}^{-3}, \quad \mathrm{ICt}_{50}\right)$, provocam o desenvolvimento de edema na córnea com deficiência visual, edema da pálpebra, fotofobia intensa e blefaroespasmo, que se inicia de 3 a 12 horas após a exposição e pode resultar em cegueira temporária. ${ }^{11} \mathrm{Em}$ doses acima de 400 $\mathrm{mg} \cdot \min . \mathrm{m}^{-3}$ ocorrem graves danos à córnea com ulceração e oclusão de vasos sanguíneos da conjuntiva, devido à lesão endotelial. A vascularização da córnea inicia-se após algumas semanas e pode levar à formação de pannus.

A Tabela 5 descreve os efeitos agudos da exposição à mostarda de enxofre em diferentes órgãos.

Tabela 5. Efeitos agudos da mostarda de enxofre em diferentes órgãos ${ }^{11}$

\begin{tabular}{|c|c|c|c|c|c|}
\hline $\begin{array}{l}\text { Severidade } \\
\text { da } \\
\text { exposição }\end{array}$ & Olhos & $\begin{array}{l}\text { Sistema } \\
\text { respiratório }\end{array}$ & Pele & $\begin{array}{l}\text { Toxicidade } \\
\text { sistêmica }\end{array}$ & Início dos efeitos \\
\hline Leve & $\begin{array}{l}\text { Conjuntivite, } \\
\text { arenosidade da } \\
\text { pálpebra, } \\
\text { lacrimejamento }\end{array}$ & $\begin{array}{c}\text { Irritação da } \\
\text { mucosa nasal, } \\
\text { rouquidão, espirro, } \\
\text { tosse }\end{array}$ & Eritema, coceira & $\begin{array}{c}\text { (náuseas e } \\
\text { vômitos) } \\
\text { Perda de apetite }\end{array}$ & $\begin{array}{c}\text { Olhos } 4-12 \mathrm{~h} \\
\text { Vias aéreas } 6-24 \mathrm{~h} \\
\text { Pele } 2-24 \mathrm{~h}\end{array}$ \\
\hline Moderada & $\begin{array}{c}\text { Edema da córnea, } \\
\text { fotofobia, severo } \\
\text { blefaroespasmo }\end{array}$ & $\begin{array}{l}\text { Lacrimejamento, } \\
\text { rinorréia, perda de } \\
\text { olfato e paladar, } \\
\text { tosse, } \\
\text { traqueobronquite, } \\
\text { pseudomembranas }\end{array}$ & $\begin{array}{l}\text { Eritema severo } \\
\text { seguido pela } \\
\text { formação da } \\
\text { bolha }\end{array}$ & --- & Olhos 3-6h \\
\hline Severa & $\begin{array}{c}\text { Danos severo a } \\
\text { córnea e ulceração, } \\
\text { perfuração }\end{array}$ & $\begin{array}{l}\text { Edema nas vias } \\
\text { aéreas superiores } \\
\text { e inferiores, } \\
\text { ulcerações }\end{array}$ & $\begin{array}{c}\text { Rápido } \\
\text { desenvolvimento } \\
\text { de eritema e } \\
\text { bolhas, ulceração } \\
\text { das estruturas } \\
\text { dérmicas }\end{array}$ & $\begin{array}{c}\text { Supressão } \\
\text { imunológica, } \\
\text { leucopenia, } \\
\text { diarreia, } \\
\text { caquexia e febre }\end{array}$ & $\begin{array}{c}\text { Olhos } 1-2 \mathrm{~h} \\
\text { Vias aéreas } 2-6 \mathrm{~h} \\
\text { Pele } 4-12 \mathrm{~h}\end{array}$ \\
\hline
\end{tabular}

O sistema respiratório é muito sensível à exposição à mostarda. A inalação da mostarda de enxofre afeta os tratos respiratório superior e inferior. Na exposição a pequenas doses ocorre irritação da mucosa nasal, rouquidão, espirros e tosse, após 4 a 6 horas. A exposição a doses moderadas provoca lacrimejamento, coriza, perda de olfato e paladar, secreção de muco do nariz e da garganta. ${ }^{8,11} \mathrm{Em}$ alguns casos, podem ocorrer danos às vias aéreas inferiores, como traqueobronquite, tosse seca e dolorosa, e formação de pseudomembranas. A exposição severa provoca edema nas vias aéreas superiores e ulcerações e necrose nas vias aéreas inferiores. A principal complicação é a possível infecção respiratória que resulta em danos no epitélio das vias aéreas. ${ }^{8,11,12,17}$

A mostarda de enxofre quando absorvida sistemicamente pode provocar danos à medula óssea e ao sistema imunológico. A ação imunossupressora favorece a infecção respiratória. ${ }^{11}$

A mostarda de enxofre tem o chamado "efeito radiomimético", isto é, produz efeitos semelhantes aos da radiação ionizante nas células e aos provocados pela radioterapia e quimioterapia. Em doses baixas provoca dor de cabeça, náusea, vômito e perda de apetite. ${ }^{9}$ Em doses mais elevadas produz danos ao trato gastrointestinal e a medula óssea, o que provoca imunossupressão, leucopenia, diarreia, febre, caquexia, e, em 
casos muito graves, excitação do SNC e convulsões. $^{8,9}$

A mostarda também pode afetar o SNC. Relatos de vítimas da I GM descrevem sintomas como: apatia, depressão, embotamento intelectual e langor. Estudos em animais evidenciaram que a exposição a elevadas doses de mostarda por inalação, por via intravenosa, subcutânea ou intramuscular a elevadas doses de mostarda provoca hiperexcitabilidade, movimentos musculares anormais, convulsões e outras manifestações neurológicas. Os animais apresentaram morte neurológica após algumas horas da exposição. ${ }^{12}$

\subsection{Lewisita}

A exposição à lewisita pode afetar a pele, olhos e vias respiratórias por contato direto, e efeitos sistêmicos ocorrem após a absorção do composto. Como os dados sobre exposição humana à lewisita são escassos, o que se sabe sobre os seus efeitos clínicos baseia-se em estudos em animais. ${ }^{17}$ Imediatamente após a exposição à lewisita, ocorre irritação dos olhos com tosse, espirros, salivação e lacrimejamento. Concentrações de $0,05-0,01 \mathrm{mg} \cdot \mathrm{cm}^{-2} \mathrm{em}$ contato com a pele, provocam eritema com vesicação algumas horas após a exposição. $\mathrm{A}$ dor na pele e nos olhos é imediata, diferente da mostarda. Os efeitos nos olhos e na pele atingem o pico entre 4 e 8 horas após a exposição. Em casos mais graves, ocorre formação de edema pulmonar e possivelmente insuficiência respiratória. Pela via dérmica pode ocorrer necrose hepática e absorção de arsênio suficiente para provocar a morte. ${ }^{17} \mathrm{~A}$ exposição ocular a levisita provoca dor imediata e blefaroespasmo. Uma pequena gota $(10 \mu \mathrm{L})$ pode provocar perfuração ocular e até perda do globo ocular. Ensaios realizados com coelhos expostos à lewisita levaram quase imediatamente a edemas nas pálpebras, conjuntiva e córnea, com envolvimento precoce e grave da íris e do corpo ciliar, seguido por despigmentação do estroma da íris. O desenvolvimento de miose ocorreu em curto período de tempo, o que não se observou em estudos realizados com o gás mostarda. Por outro lado não se verificou efeitos oculares da lewisita a longo prazo, ao contrário do mostarda que tem como efeito ocular a longo prazo o desenvolvimento de ceratite (inflamação da córnea). ${ }^{17}$

A ingestão de alimentos contaminados com lewisita pode provocar os sintomas e sinais de envenenamento por arsênio, que incluem: dor de estômago, vômitos, diarreia, dormência e formigamento nos pés, sede e câimbras musculares. A intoxicação aguda por arsênio inclui também: neuropatia, nefrite com proteinúria, encefalopatia, anemia hemolítica intravascular, hemólise e, em casos extremos, insuficiência renal. ${ }^{22}$

O contato com a lewisita na forma líquida ou vapor, provoca dor e irritação segundos após a exposição. A dor provocada pelo agente é menos aguda se comparada com a provocada pela mostarda, e diminui após a formação das vesicações. Após a exposição ao líquido, ocorre a formação de eritema entre 15 e 30 minutos. A formação de vesicações ocorre horas após a exposição. 0 tempo será um pouco maior no caso do vapor da lewisita. Esse agente é absorvido pela pele em 3 a 5 minutos (em comparação com 20 a 30 minutos para uma quantidade equivalente de mostarda) e se espalha por uma área maior que a da mostarda. ${ }^{11,22} \mathrm{~A}$ formação das vesicações inicia-se com o desenvolvimento no centro da área eritematosa, de uma pequena bolha que se expande e desencadeia o processo inflamatório. Diferente da vesicação provocada pelo gás mostarda, esse processo começa como um "colar" de pequenas bolhas na periferia da lesão que depois se fundem em uma bolha maior. Outras diferenças entre as lesões produzidas pela lewisita e pelo gás mostarda são: 1) A reação inflamatória da lewisita ocorre mais rápido; 2) As lesões se curam mais facilmente; 3) A infecção secundária é menos comum após a exposição à lewisita; 4) A hiperpigmentação ou 
hipopigmentação é menos comum em casos de exposição à lewisita. ${ }^{12,22}$

O vapor de lewisita é extremamente irritante para o nariz e vias aéreas inferiores. A lesão das vias aéreas provocadas pela lewisita é muito semelhante às provocadas pelo gás mostarda. O vapor de lewisita provoca espirro, tosse, sufocação e necrose e, em quantidade elevadas, provoca edema pulmonar. Experimentos realizados com cães expostos ao gás de lewisita evidenciaram a formação de secreções nasais, lacrimejamento, ânsia de vômito, respiração ofegante e esses sintomas se intensificaram até ocorrer a morte dos animais. A autópsia evidenciou pulmão edematoso, com formação de pseudomembrana desde as narinas até os brônquios. A mucosa brônquica e traqueal estava destruída e a submucosa edematosa, com broncopneumonia. ${ }^{12}$

\subsection{Fosgênio oxima}

A fosgênio oxima afeta a pele, olhos e pulmões causando dor e irritação imediata. Os efeitos são quase instantâneos e os danos provocados aos tecidos são mais graves que com outros vesicantes. Nenhum outro agente químico de guerra produz dores imediatamente seguidas por necrose, como a fosgênio oxima. ${ }^{11}$

Depois da exposição à pele, ocorre formação de eritema, pápulas e urticária. 0 local torna-se cinzento com a formação, no período de 5 a 30 minutos da exposição, de eritema e de edema, aparecendo bordas ao redor do local (pápulas), e o tecido necrosase. O edema regride após 24 horas da exposição, as áreas esbranquiçadas da pele ficam marrons e forma-se uma crosta. A dor e a coceira permanecem durante todo o processo de cicatrização. ${ }^{11}$

As lesões oculares da fosgênio oxima são semelhantes àquelas causadas pela lewisita. Após a exposição ocorre dor, irritação, lacrimejamento e, em alguns casos, cegueira temporária. Essas lesões resultam em conjuntivite e queratite (inflamação da córnea). ${ }^{11}$

A principal lesão da fosgênio oxima nos pulmões é o edema pulmonar. Este efeito ocorre após a inalação ou absorção sistêmica do agente, com irritação imediata, coriza, rouquidão e dor sinusal. 0 edema pulmonar pode ser acompanhado por bronquiolite necrosante e trombose pulmonar.

\section{Tratamento e descontaminação}

Ainda não se conhece antídoto contra a intoxicação por agentes vesicantes e a única forma de tratamento disponível é a eliminação dos sintomas. A vítima deve ser imediatamente removida do local contaminado e passar por um processo de descontaminação para reduzir o contato com o agente. ${ }^{9}$ Isso tem de ser feito nos primeiros 5 minutos após o contato, caso contrário o procedimento será inútil devido à rápida penetração da mostarda, principalmente nos olhos. A descontaminação da pele é feita com terra de fuller, solventes orgânicos ou cloramina T. Para os olhos usa-se solução salina ou água, vaselina, para evitar a colação das pálpebras, e antibióticos. Os eritremas e as bolhas podem ser tratados com caladril ${ }^{\circledR} \mathrm{e}$ as coceiras com anti-histamínicos. ${ }^{9} \mathrm{~A}$ dor é tratada com analgésicos e até mesmo morfina, dependendo da gravidade da contaminação. Os potenciais focos de infecção podem ser tratados com sulfadiazina de prata. Para restaurar o aparelho respiratório pode-se usar codeína contra a tosse e antibióticos. Quando há depressão da medula óssea há necessidade de administração de estimulantes para reativála. ${ }^{9}$

Atualmente investiga-se medicamentos que possam impedir o processo bioquímico de lesão das mostardas (Figura 6). Os compostos pesquisados $^{12}$ são: 1) Os chamados sequestradores intracelulares, como a $\mathrm{N}$-acetilcisteína e a aminofostina; 2) Os inibidores do ciclo celular, como a mimosina; 3) Os inibidores da PARP, como a 
niacinamida; 4) Os moduladores de cálcio, como o BAPTA; 5) Os inibidores de protease, como o ilomastat ${ }^{\circledR}$; e 6) Compostos com ação anti-inflamatória, como a indometacina.
Porém, ainda não existe um antídoto específico para as lesões provocadas pelas mostardas.<smiles>CC(=O)C(CS)C(=O)O</smiles>

$N$-acetilcisteína<smiles>NCCCNCCSP</smiles>

Aminofostina<smiles>NC(Cn1ccc(=O)c(O)c1)C(=O)O</smiles>

Mimosina<smiles>NC(=O)c1cccnc1</smiles>

Niacinamida<smiles>O=C(O)N(C(=O)O)c1cccc(OCCOc2cccc(N(C(=O)O)C(=O)O)c2)c1</smiles>

BAPTA<smiles>CNC(=O)C(Cc1c[nH]c2ccccc12)C(=O)NC(CC(=O)NO)CC(C)C</smiles>

llomastat<smiles>COc1ccc2c(c1)c(CC(=O)O)c(C)n2C(=O)c1ccc(Cl)cc1</smiles>

Indometacina

Figura 6. Estruturas dos potenciais inibidores do processo bioquímico de lesão da mostarda de enxofre

Durante a II GM os Ingleses desenvolveram um antídoto contra o envenenamento sistêmico por arsênio provocado pelas lewisitas, muito eficiente se for usado minutos após a exposição, que foi batizado de BAL (British Anti Lewisite). ${ }^{22}$ Trata-se de um agente quelante homólogo ao glicerol, o dimercaprol, que é capaz de se ligar ao arsênio (Figura 7) mais fortemente do que as enzimas, reduzindo, assim, sua biodisponilibidade. Efeitos colaterais passageiros são irritação da pele, hipertensão, taquicardia e impressão de constrição no peito. O DMSA (ácido meso2,3-dimercaptosuccínico) e o DMPS (ácido 2,3-dimercapto-1-propanossulfônico) (Figura 8) são análogos solúveis em água e menos tóxicos que o dimercaprol que podem ser administrados por via oral. o 2,3-ditioeritrol (DTE) (Figura 8) também é um descontaminante promissor.

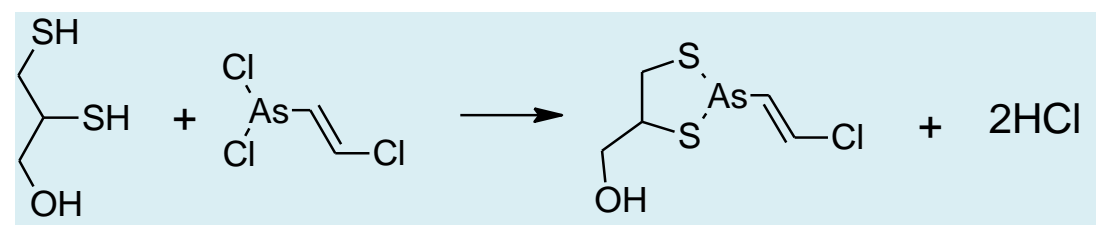

Figura 7. Ação quelante do dimercaprol com a lewisita. 


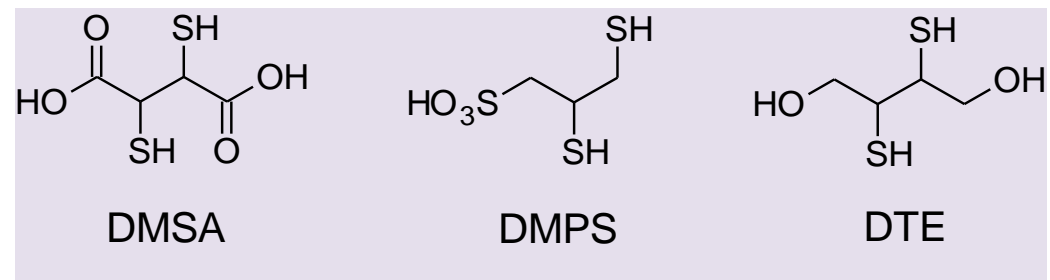

Figura 8. Estruturas de alguns agentes quelantes de lewisita

\section{Considerações finais}

Os vesicantes são agentes de guerra química extremamente perigosos. Seu uso em batalhas desde a I GM mundial chocaram - mundo com as horríveis queimaduras químicas que são capazes de provocar. Essas queimaduras deixam sequelas graves que podem desfigurar suas vítimas e, muitas vezes, torná-las inválidas. Fato que aliado a sua facilidade de obtenção, ação rápida e à inexistência de um antídoto, tornam os vesicantes muito atraentes para grupos terroristas interessados em disseminar o pânico. Foi objetivo dessa revisão, portanto, chamar a atenção da Sociedade Brasileira para esse perigo e contribuir para estimular a comunidade científica a pesquisar novos antídotos e formas de tratamento contra os vesicantes.

\section{Agradecimentos}

Os autores agradecem ao Conselho Nacional de Desenvolvimento Científico e Tecnológico (CNPq), a Fundação de Amparo à Pesquisa do Estado do Rio de Janeiro (FAPERJ), a Coordenação de Aperfeiçoamento de Pessoal de Nível Superior / Ministério da Defesa (CAPES / MD) (Edital PRODEFESA 2008) pelo apoio financeiro, e ao Instituto Militar de Engenharia (IME) pela infraestrutura física e o espaço de trabalho.

\section{Referências Bibliográficas}

${ }^{1}$ Smart, J. M.; Em Medical aspects of chemical and biological warfare; Sidell, F. R.; Takafuji, E. T.; Franz, D. R. eds.; Borden Institute: Washington DC, 1997. cap 2.

${ }^{2}$ Eckert, W. Mass deaths by gás or chemical poisoning. A historical perspective. American Journal of Forensic Medicine and Pathology 1991, 12, 119.

${ }^{3}$ Schecter, W.; Fry, D. E. The Surgeon and acts of civilian terrorism: Chemical agents. Journal of the American College of Surgeons 2005, 200, 128. [CrossRef]

${ }^{4}$ Chauhan, S.; Chauhan, S.; D'Cruz, R.; Faruqi, S.; Singh, K. K.; Varma, S.; Singh, M.; Karthik, V. Chemical warfare agents. Environmental Toxicology and Pharmacology 2008, 26, 113. [CrossRef]

${ }^{5}$ Colasso, C.; Azevedo, F. A. Riscos da utilização de armas químicas. Parte 1 Histórico. Revista Intertox de Toxicologia, Risco Ambiental e Sociedade, 2011, 4, 137. [Link]

${ }^{6}$ Hilmas, C. J.; Smart, J. K.; Hill, B. Em Medical aspects of chemical warfare. Tuorinsky. S. D. ed.; Borden Institute: Washington, DC, 2008. cap 2.

${ }^{7}$ Fitzgerald. G. J. Chemical warfare and medical response during world war I. American Journal of Public Health, 2008, 98, 611. [CrossRef]

${ }^{8}$ Pita, R. Vidal-asensi, S. Cutaneous and systemic toxicology of vesicant (Blister) warfare agents. ACTAS Dermo-Sifiliográficas 2010, 101, 7. [CrossRef]

${ }^{9}$ McManus. J.; Facep M.; Huebner. K. Vesicants. Critical Care Clinics 2005, 21, 707. [CrossRef] 
${ }^{10}$ Szinicz, L. History of chemical and biological warfare agents. Toxicology 2005, 214, 167. [CrossRef]

${ }^{11}$ Hurst, C. G.; Em: Tuorinsky, C. ed.;. Medical aspects of chemical warfare. Borden Institute: Washington, DC, 2008. cap 8.

${ }^{12}$ Kehe, K; Szinicz. L. Medical aspects of sulphur mustard poisoning. Toxicology 2005, 214, 198. [CrossRef]

${ }^{13}$ Sítio da Organisation for the Prohibition of Chemical Weapons. Disponível em: <http://www.opcw.org/about-opcw/>.

Acessado em: 11 abril 2014.

${ }^{14}$ França, T. C. C.; Silva, G. R.; Castro, A. T. Defesa química: Uma nova disciplina no ensino de química. Revista Virtual de Química 2010, 2, 84. [CrossRef]

${ }^{15}$ Kehe, K.; Thiermann, H.; Balszuweit, F.; Eyer, F.; Steinritz, D.; Zilker, T. Acute effects of sulfur mustard injury-Munich experiences. Toxicology 2009, 263, 3. [CrossRef]

${ }^{16}$ Pita. R.; Contelles, J. M.; Ramos, E.; Del Pino, J.; Romero, A. Toxicity induced by chemical warfare agents: Insights on the protective role of melatonine. ChemicoBiological Interactions 2013, 206, 134. [CrossRef]

${ }^{17}$ Marrs, T. C.; Maynard, R. L.; Sidell, F.R.; Chemical warfare agents - Toxicology and treatment, 1st ed., John Wiley \& Sons: Chichester, 2007.

${ }^{18}$ Bijani, K.; Moghadamnia, A. A.; Long term effects of chemical weapons on respiratory tract Iraq-Iran war victims living in Babol (North of Iran). Ecotoxicology and Environmental Safety 2002, 53, 422. [CrossRef]

${ }^{19}$ Ghazanfari, T. Ghazanfari, T.; Faghihzadeh S.; Aragizadeh, H.; Soroush M. R.; Yaraee, R.; Hassan, Z. M.; Foroutan, A.; Vaez-Mahdavi M. R.; Javadi, M. A.; Moaiedmohseni, S.; Azizi, F.; Panahi, Y.; Mostafaie, A.; Ghasemi, H.; Shams, J.; Pourfarzam, S.; Jalali-Nadoushan, M. R.; Fallahi, F.; Ebtekar, M.; Davoudi, S. M.; Ghazanfari, Z.; Ardestani S. K.; Shariat-Panahi. S.; Moin, A.; Rezaei, A.; Kariminia, A.; Ajdary, S.; Mahmoudi, M.; Roshan, R.; Ghaderi, S.; Babai, M.; Naghizadeh, M. M.; Ghanei, M. and the Sardasht-Iran Cohort Study Research Group. Sardasht-Iran cohort study of chemical warfare victims: design and methods. Archives Iranian Medicine 2009, 12, 5. [CrossRef]

${ }^{20}$ Yong, R.; Bast, C. Em: Gupta, R. M. ed.; Handbook of toxicology of chemical warfare agents. $1^{\text {st }}$ ed.; Academic Press: London, 2009, cap 8.

${ }^{21}$ Azevedo, F. A.; Chasin, A. A. M. eds.; Metais, gerenciamento da toxicidade, 1st ed.; Atheneu: São Paulo, 2003.

${ }^{22}$ Swaran J. S. F.; Govinder F.; Geetu, S. Em: Gupta, R. M. ed.; Handbook of toxicology of chemical warfare agents. $1^{\text {st }}$ ed.; Academic Press: London, 2009, cap 9. 